medRxiv preprint doi: https://doi.org/10.1101/2021.12.06.21267289; this version posted December 13, 2021. The copyright holder for this preprint (which was not certified by peer review) is the author/funder, who has granted medRxiv a license to display the preprint in perpetuity. It is made available under a CC-BY 4.0 International license .

Running Head: TESTING VACCINE ATTITUDE MEASURE

\title{
Testing the Validity of the Modified Vaccine Attitude Question Battery across 22 Languages with a Large-scale International Survey Dataset: Within the Context of COVID-19 Vaccination
}

\author{
Hyemin $\operatorname{Han}^{\mathrm{a} *}$ \\ ${ }^{a}$ Educational Psychology Program, University of Alabama, Tuscaloosa, United States \\ of America
}

*Corresponding: Educational Psychology Program, University of Alabama, Box

870213, Tuscaloosa, AL 35487, United States of America. Email: hyemin.han@ua.edu 


\section{Testing the Validity of the Modified Vaccine Attitude Question Battery across 22 Languages with a Large-scale International Survey Dataset: Within the Context of COVID-19 Vaccination}

In this study, we tested the validity of the modified version of the Vaccine Attitude Question Battery (VAQB) across 22 different languages. Validity test was conducted with a large-scale international survey dataset, COVIDiSTRESSII Global Survey, collected from 20,601 participants from 62 countries. We employed exploratory and confirmatory factor analysis, measurement invariance test, and measurement alignment for internal validity test. Moreover, we examined correlation between the VAQB score, vaccination intent, compliance with preventive measures, and trust in public health-related agents. The results reported that the modified VAQB, which included five items, showed good validity across 22 languages with measurement alignment. Furthermore, the VAQB score showed negative association with vaccination intent, compliance, and trust as expected. The findings from this study provide additional evidence supporting the validity of the modified VAQB in 22 languages for future largescale international research on COVID-19 and vaccination.

Keywords: COVID-19; Vaccine Attitude; Psychometrics; Validation; International Survey; Measurement alignment

\section{Introduction}

COVID-19 vaccines have been reported as an effective and reliable mean to prevent COVID-19 caused hospitalization and death across the globe ${ }^{1}$. Although scientific research has consistently supported their safety and effectiveness, negative attitudes toward vaccines have become a serious issue ${ }^{2}$. Because how to deal with such negative attitudes is one of the most fundamental problems that shall be addressed to promote wide distribution of the COVID-19 vaccines, and eventually, to end the COVID-19 pandemic, it is necessary to have a reliable and valid way to examine vaccine attitude. For example, ${ }^{3}$ developed and tested the Vaccination Hesitancy Scale (VHS) consisting of ten items; in the study, the VHS was validated in two languages, English and French, 
among Canadian populations. Since its development, the VHS has been widely employed in studies focusing on people's attitude on vaccination ${ }^{4}$.

Although the VHS has been tested in validated in prior research, whether it can be applicable across different languages in a consistent way has not been fully examined. Given the COVID-19 pandemic is a global issue, international and crosscultural research is strongly required. The majority of the previous studies employing the VHS tested the scale within a single-language study context, so they would not sufficiently support cross-language validity of the scale, which requires for international and cross-cultural comparisons or investigations ${ }^{5}$. Similarly, other scales that have been less employed than the VHS have not been well tested for their validity in multi-lingual settings (e.g., $\left.{ }^{2}\right)$.

In this study, we aimed at testing the validity of the Vaccine Attitude Question Battery (VAQB), which was modified from the original VAQB employed in a largescale survey regarding vaccine attitude conducted in $2020^{2}$, across different languages by examining a large-scale dataset, COVIDiSTRESSII Global Survey (COVIDiSTRESSII), collected 20,601 participants from 62 countries ${ }^{6}$. First, we performed exploratory and confirmatory factor analysis (EFA and CFA) with the English version of the modified VAQB. Second, we conducted measurement invariance (MI) test across 22 languages to examine whether the measurement structure of the modified VAQB was valid across different languages. Third, we performed measurement alignment to address the existing measurement non-invariance. Finally, we examined correlation between the calculated VAQB score and other variables that are expected to be positively associated with positive vaccine attitude, i.e., vaccination intent, compliance with preventive measures, trust in public health-related agents ${ }^{7,8}$. 


\section{Methods}

\section{Analyzed Dataset}

COVIDiSTRESSII dataset was collected from 20,601 participants using 48 different languages across the globe (see Supplementary Methods for further details about translation, data collection, and data preprocessing procedures) ${ }^{6}$. For MI test and measurement alignment, which involve CFA, only the language versions with $N \geq 200$ were analyzed. As a result, responses from 14,271 participants using 22 different languages were used in the present study (see Table S1 for the list of languages and demographics). Further details about the original dataset collection and preprocessing procedures are available in COVIDiSTRESSII project page, https://osf.io/36tsd.

COVIDiSTRESSII project was reviewed and approved by the Research, Enterprise and Engagement Ethical Approval Panel at University of Salford (ref.: 1632).

\section{Measures}

All measures were translated into different languages by COVIDiSTRESSII Consortium members. Further details about the employed measures are available in Supplementary Methods.

\section{Modified Vaccine Attitude Question Battery}

The modified VAQB with six item was employed to assess participants' attitude to get COVID-19 vaccines. The six items were extracted and modified from the original $\mathrm{VAQB}^{2}$ for a feasibility within the context of the large-scale international survey project based on discussions between COVIDiSTRESSII Consortium members. Responses were anchored to a seven-point Likert scale (1-strongly disagree to 7strongly agree). Four items, Items 4 and 5 were reverse coded. 


\section{Vaccination Intent}

Intent to get COVID-19 vaccines was assessed one item. Responses were anchored to a five-point Likert scale (1—not willing at all to 5-very willing).

Items for Compliance with Preventive Measures

We surveyed participants' compliance with non-pharmaceutical measures to prevent spread of COVID-19. These items were adapted from the previous round of COVIDiSTRESS Global Survey ${ }^{9,10}$. We examined compliance in three different behavioral domains, i.e., indoor and outdoor mask use, social distancing. Each type of compliance was measured with one item. Responses were anchored to a seven-point Likert scale (1—-strongly disagree to 7 -strongly agree).

\section{Items for Trust}

Participants' trust in four different agents, i.e., health system, the World Health Organisation (WHO), governmental effort to handle the pandemic, science research, related to vaccination was also assessed. Similar to the items for compliance, the trust items were also adapted from COVIDiSTRESS Global Survey ${ }^{9,10}$. Trust in each agent was surveyed with one item. Responses were anchored to a 11-point Likert scale ( 0 -no trust to 10 - complete trust).

\section{Analysis Plan}

In this section, we described how the reliability and validity of the modified VAQB were tested. All R source code and data files are available to the public via the Open Science Framework, https://doi.org/10.17605/OSF.IO/QCPZX. 
medRxiv preprint doi: https://doi.org/10.1101/2021.12.06.21267289; this version posted December 13, 2021. The copyright holder for this preprint (which was not certified by peer review) is the author/funder, who has granted medRxiv a license to display the preprint in perpetuity.

It is made available under a CC-BY 4.0 International license.

Running Head: TESTING VACCINE ATTITUDE MEASURE

\section{Exploratory and Confirmatory Factor Analysis}

The whole English version dataset was randomly separated into two subsets, one for EFA $(50 \%)$ and one for CFA (50\%), to prevent overfitting. Then, we performed EFA of the modified VAQB with the first subset with R packages, EFA.dimensions and EFAtools. First, we tested whether EFA can be adequately performed with KaiserMeyer-Olkin (KMO) and Bartlett's test. Second, we employed diverse measures, i.e., parallel analysis (PA), minimum average partial (MAP) test, hull method, KaiserGuttman criterion (KGC), to determine the number of factors to be explored ${ }^{11}$. Third, we performed EFA with the determined factor number. In general, we assumed that factor loadings smaller than .50 as inappropriate ${ }^{12}$.

Then, we conducted CFA with the second subset. CFA was performed with the measurement model identified by EFA with lavaan package. Because responses were anchored to a Likert scale, we employed $W L S M V$ estimator, which is suitable for CFA with ordinal responses. CFA was conducted again with the whole data with the model. I examined whether RMSEA and SRMR $<.08$ and CFI and TLI $\geq .90$ at the least ${ }^{13}$.

Furthermore, we also investigated whether each factor loading was significant at $p<.05$

${ }^{12}$. If the aforementioned requirements for EFA and CFA indicators were not fulfilled, we revised the modified VAQB by adjusting items and examined the fit indicators once again with the modified version.

Additionally, we examined the internal consistency of the modified VAQB across different languages in term of Cronbach $\alpha$. The brief descriptive statistics and internal consistency of the modified VAQB in $\alpha$ for each language version are presented in Table S1. 


\section{Measurement Invariance Test}

MI test was performed to examine whether the measurement model of the modified VAQB validated in the English version can also be validated across different language versions. It was performed by setting the group variable and equal parameter conditions in lavaan.

There are different levels of MI depending on the different equal parameter assumption. First, configural invariance only assumes the equal measurement structure across different groups. Second, metric invariance additionally assumes that factor loadings are equal. Third, scalar invariance additionally requires equal intercepts. Finally, the strictest invariance, scalar invariance, is achieved when the equal residual assumption is additionally satisfied ${ }^{14}$.

Whether a specific level of invariance was achieved was examined by comparing fit indicators, i.e., RMSEA, SRMR, CFI, TLI, between two different levels of invariance. In the case of metric invariance, indicator changes should be smaller than -.01 CFI, +.015 RMSEA, and +.30 SRMR. For scalar invariance, changes should be less than -.01 CFI, +.015 RMSEA, and +.15 SRMR ${ }^{15}$. For between-group comparison, scalar invariance must be satisfied at the least ${ }^{5}$.

\section{Measurement Alignment}

If scalar invariance was not supported in the MI test, we performed measurement alignment to address the existing non-invariance. We employed sirt package to implement measurement alignment in $\mathrm{R}^{5}$. Measurement alignment is a procedure to adjust factor loadings, intercepts, and group means to address non-invariance ${ }^{5,16}$. To examine whether non-invariance was successfully addressed, we checked whether the

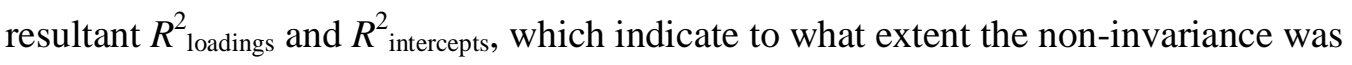
absorbed via measurement alignment, approached $100 \%{ }^{16,17}$. If both $R^{2}$ values 
exceeded $95 \%$ as shown in the prior research using measurement alignment ${ }^{18}$, we assumed achievement of scalar invariance through measurement alignment ${ }^{16,17}$. Then, we calculated an adjusted VAQB factor score for each language group with adjusted factor loadings and intercepts. The factor score was calculated with the pseudo inverse matrix of factor loadings with MASS package ${ }^{19}$.

\section{Correlation Analysis}

We conducted correlation analysis to acquire additional evidence supporting the convergent validity of the modified VAQB. Correlation between the VAQB score and other surveyed variables, vaccination intent, compliance, and trust, which were supposed to be positively associated with vaccine attitude ${ }^{7,8}$, was examined. We assumed that the convergent validity of the VAQB was supported once significant positive correlation between the vaccine attitude, vaccination intent, compliance, and trust was found. For additional information, correlation between the VAQB items was also investigated.

\section{Results}

\section{Exploratory and Confirmatory Factor Analysis}

Both KMO, .82, and Bartlett's test, $\chi^{2}(15)=1,545.28, p<.001$, indicated that EFA was able to be adequately performed with the current scale and first English-version subset. All factor number determination methods, i.e., PA, MAP test, hull method, KGC, unequivocally suggested that only one factor was sufficient in the measurement model. The result of EFA with the one-factor model is presented in Table 1. Because the factor loading of Item 4 did not exceed the cutoff, .50, we conducted CFA with caution.

Table 1. Standardized factor loading resulting from EFA and CFA
6-item VAQB
5-item VAQB 


\begin{tabular}{llllll} 
& $\begin{array}{l}\text { EFA } \\
\text { (English) }\end{array}$ & $\begin{array}{l}\text { CFA } \\
\text { (English) }\end{array}$ & \multicolumn{2}{l}{$\begin{array}{l}\text { CFA } \\
\text { (English) }\end{array}$} & \multicolumn{2}{l}{$\begin{array}{l}\text { CFA } \\
\text { (whole) }\end{array}$} \\
\hline Item 1 & .78 & .79 & .84 & .89 \\
Item 2 & .70 & .76 & .79 & .81 \\
Item 3 & .58 & .60 & .63 & .60 \\
Item 4 & .44 & .42 & - & & - \\
Item 5 & .61 & .59 & .51 & .58 \\
Item 6 & .78 & .64 & .66 & .84 \\
\hline
\end{tabular}

When CFA was performed with the second English-version subset, the original measurement model including all six items did not report good model fit indicators, RMSEA $=.15$, PCLOSE $=.00$, SRMR $=.06, \mathrm{CFI}=.75, \mathrm{TLI}=.58$. Thus, we excluded the fourth item that showed the lowest standardized factor loading (.42) and did not show the satisfactory factor loading from EFA.

Hence, we performed CFA once again with the updated version with five items. The modified five-item scale well fitted the data, RMSEA $=.04$, PCLOSE $=.69$, SRMR $=.02, \mathrm{CFI}=.99, \mathrm{TLI}=.98$. All factor loading reported $p<.001$. When CFA was performed with the whole dataset with the five-item model, acceptable model fit indicators were reported as well, RMSEA $=.07, \mathrm{PCLOSE}=.00, \mathrm{SRMR}=.02, \mathrm{CFI}$ $=.98, \mathrm{TLI}=.96$. Similar to the case of the English version, all factor loadings demonstrated $p<.001$. All resulting standardized factors loadings are presented in Table 1.

\section{Measurement Invariance Test}

When configural invariance was tested, the resultant model fit indicators suggested mediocre fit, RMSEA $=.09$, PCLOSE $=.00$, SRMR $=.03, \mathrm{CFI}=.93, \mathrm{TLI}=.87$. With the equal loading assumption, metric invariance was tested. However, the model did not fit data well, RMSEA $=.11, \mathrm{PCLOSE}=.00, \mathrm{SRMR}=.09, \mathrm{CFI}=.81, \mathrm{TLI}=.78$. Additionally, the large changes in RMSEA (+.02), SRMR (+.06), CFI (-.12), and TLI (.08), suggested metric invariance could not be achieved. Given scalar invariance, which is minimally required for between-group comparison, could not be supported by data, 
we performed measurement alignment to address the non-invariance across different languages.

\section{Measurement Alignment}

The results from measurement alignment demonstrated that measurement noninvariance across different languages was successfully resolved by adjusting factor loadings and intercepts. The resultant $R_{\text {loadings }}^{2}=.97$ and $R_{\text {intercepts }}^{2}=.98$. They indicate that approximately $100 \%$ of existing non-invariance was absorbed by latent factor means and variances varying across languages, and thus, scalar invariance can be achieved via measurement alignment.

\section{Correlation Analysis}

Correlation between surveyed variables, the VAQB factor score, general vaccination intent, compliance, and trust, is presented in Table 2. As expected, vaccine attitude was positively associated with all other variables, so the convergent validity of the modified VAQB was supported. Moreover, all VAQB items showed significant correlation with each other (see Table S2).

Table 2. Correlation between the VAQB factor score and indicators related to vaccination intent, trust, and compliance with non-pharmaceutical preventive measures

\begin{tabular}{llllllllll}
\hline & & 1 & 2 & 3 & 4 & 5 & 6 & 7 & 8 \\
\hline 1. VAQB & & - & & & & & & & \\
2. Vaccination intent & .78 & - & & & & & & \\
& 2. Health system & .39 & .37 & - & & & & & \\
\multirow{2}{*}{ Trust } & 3. WHO & .40 & .38 & .51 & - & & & & \\
& 4. Governmental effort & .31 & .28 & .57 & .46 & - & & & \\
& 5. Scientific research & .58 & .52 & .55 & .61 & .47 & - & & \\
\multirow{4}{*}{ Compliance } & 6. indoor mask use & .45 & .42 & .23 & .26 & .19 & .34 & - & \\
& 7. outdoor mask use & .26 & .30 & .08 & .09 & .04 & .13 & .50 & - \\
& 8. social distancing & .29 & .28 & .13 & .18 & .14 & .21 & .44 & .44 \\
\hline
\end{tabular}

Note. All correlation reported $p<.05$ after false discovery rate correction. 
medRxiv preprint doi: https://doi.org/10.1101/2021.12.06.21267289; this version posted December 13, 2021. The copyright holder for this preprint (which was not certified by peer review) is the author/funder, who has granted medRxiv a license to display the preprint in perpetuity.

It is made available under a CC-BY 4.0 International license.

Running Head: TESTING VACCINE ATTITUDE MEASURE

\section{Discussion}

In this study, we tested the validity of the modified VAQB across 22 different

languages. We found that the original measurement model should be modified to achieve good model fit, so one item was excluded from the original six-items scale. The five-item scale reported acceptable model fit. However, measurement non-invariance was reported from the MI test. When measurement alignment was performed, the existing non-invariance was successfully absorbed; the large resultant $R^{2}$ values suggest achievement of scalar invariance through measurement alignment ${ }^{18}$. The correlation analysis demonstrated that the calculated factor score of vaccine attitude after alignment was positively associated with general vaccination intent, compliance with nonpharmaceutical preventive measures, and trust in health organizations, governmental efforts, and science research, in line with previous research ${ }^{7,8}$.

Although the findings suggested the potential utility of the modified VAQB, several limitations warrant further investigations. First, although our dataset is a largescale international survey dataset, it has been collected via convenient samples (i.e., internet users). Thus, the generalizability of the findings could be limited due to the sample quality and bias issues. Second, we employed self-report measures for vaccine intent and compliance, so predictive validity in terms of whether the measured vaccine attitude can predict actual behavioral outcomes could not be fully supported.

\section{Conclusion}

The modified VAQB, which contains five items, can be reliably and validly administrated in 22 different languages with assistance of measurement alignment addressing measurement non-invariance. Because the version with six items did not show good psychometrical quality, we excluded one item and re-tested the version with five items. The correlational analysis also provides additional evidence supporting the 
medRxiv preprint doi: https://doi.org/10.1101/2021.12.06.21267289; this version posted December 13, 2021. The copyright holder for this preprint (which was not certified by peer review) is the author/funder, who has granted medRxiv a license to display the preprint in perpetuity.

It is made available under a CC-BY 4.0 International license .

Running Head: TESTING VACCINE ATTITUDE MEASURE

convergent validity of the scale. In conclusion, the modified VAQB will be able to be

widely utilized in future large-scale international studies regarding COVID-19

vaccination, particularly those involving cross-cultural or cross-national comparisons,

with measurement alignment.

Acknowledgements: The author thanks Sara Vestergren and COVIDiSTRESSII Global

Survey Consortium members for their help regarding data collection and preprocessing.

Disclosure statement: No potential conflict of interest was reported by the author.

\section{References}

1. Tregoning JS, Flight KE, Higham SL, Wang Z, Pierce BF. Progress of the

COVID-19 vaccine effort: viruses, vaccines and variants versus efficacy,

effectiveness and escape. Nature Reviews Immunology 2021; 21.

2. Guess AM, Nyhan B, O'Keeffe Z, Reifler J. The sources and correlates of exposure to vaccine-related (mis)information online. Vaccine 2020; 38.

3. Shapiro GK, Tatar O, Dube E, Amsel R, Knauper B, Naz A, Perez S, Rosberger

Z. The vaccine hesitancy scale: Psychometric properties and validation. Vaccine $2018 ; 36$.

4. Oduwole EO, Pienaar ED, Mahomed H, Wiysonge CS. Current tools available for investigating vaccine hesitancy: a scoping review protocol. BMJ Open 2019;

9.

5. Fischer R, Karl JA. A Primer to (Cross-Cultural) Multi-Group Invariance Testing Possibilities in R. Frontiers in Psychology 2019; 10.

6. Blackburn AM, Vestergren S, COVIDiSTRESS II Consortium. COVIDiSTRESS diverse dataset on psychological and behavioural outcomes one year into the COVID-19 pandemic. 2021; 
medRxiv preprint doi: https://doi.org/10.1101/2021.12.06.21267289; this version posted December 13, 2021. The copyright holder for this preprint (which was not certified by peer review) is the author/funder, who has granted medRxiv a license to display the preprint in perpetuity. It is made available under a CC-BY 4.0 International license .

Running Head: TESTING VACCINE ATTITUDE MEASURE

7. Soveri A, Karlsson LC, Antfolk J, Lindfelt M, Lewandowsky S. Unwillingness to engage in behaviors that protect against COVID-19: the role of conspiracy beliefs, trust, and endorsement of complementary and alternative medicine. BMC Public Health 2021; 21.

8. Latkin CA, Dayton L, Yi G, Colon B, Kong X. Mask usage, social distancing, racial, and gender correlates of COVID-19 vaccine intentions among adults in the US. PLOS ONE 2021; 16.

9. Yamada Y, Ćepulić D-B, Coll-Martín T, Debove S, Gautreau G, Han H, Rasmussen J, Tran TP, Travaglino GA, Lieberoth A. COVIDiSTRESS Global Survey dataset on psychological and behavioural consequences of the COVID-19 outbreak. Scientific Data 2021; 8:3.

10. Lieberoth A, Lin S-Y, Stöckli S, Han H, Kowal M, Chrona S, Gelpi R, Tran TP, Jeftić A, Rasmussen J, et al. Stress and worry in the 2020 coronavirus pandemic: Relationships to trust and compliance with preventive measures across 48 countries. Royal Society Open Science 2021; 8:200589.

11. McGrath RE, Brown M, Westrich B, Han H. Representative Sampling of the Via Assessment Suite for Adults. Journal of Personality Assessment 2021; :1-15.

12. Baxter R, Woodside AG. Interfirm Business-to-Business Networks: Theory, Strategy, and Behavior. Emerald Group Publishing; 2011.

13. $\mathrm{Hu} \mathrm{L}$, Bentler PM. Cutoff criteria for fit indexes in covariance structure analysis: Conventional criteria versus new alternatives. Structural Equation Modeling: A Multidisciplinary Journal 1999; 6:1-55.

14. Putnick DL, Bornstein MH. Measurement invariance conventions and reporting: The state of the art and future directions for psychological research. Developmental Review 2016; 41:71-90. 
15. Rachev NR, Han H, Lacko D, Gelpí R, Yamada Y, Lieberoth A. Replicating the Disease framing problem during the 2020 COVID-19 pandemic: A study of stress, worry, trust, and choice under risk. PLOS ONE 2021; 16.

16. Robitzsh A. Package "sirt" [Internet]. 2021 [cited 2021 Sep 26]; Available from: https://cran.r-project.org/web/packages/sirt/sirt.pdf

17. Asparouhov T, Muthén B. Multiple-Group Factor Analysis Alignment. Structural Equation Modeling: A Multidisciplinary Journal 2014; 21:495-508.

18. Han H. Exploring the association between compliance with measures to prevent the spread of COVID-19 and big five traits with Bayesian generalized linear model. Personality and Individual Differences 2021; 176:110787.

19. DiStefano C, Zhu M, Mîndrilă D. Understanding and Using Factor Scores: Considerations for the Applied Researcher. Practical Assessment, Research, and Evaluation 2009; 14:20. 